\title{
Outcome of third-line sunitinib after sequential therapy with cytokines and sorafenib in metastatic renal cell carcinoma
}

\author{
TETSUO FUJITA, TAKAHIRO HIRAYAMA, MORIHIRO NISHI, KAZUMASA MATSUMOTO, \\ KAZUNARI YOSHIDA and MASATSUGU IWAMURA
}

Department of Urology, Kitasato University School of Medicine, Sagamihara, Kanagawa 252-0374, Japan

Received January 7, 2019; Accepted May 22, 2019

DOI: $10.3892 / \mathrm{mco} .2019 .1924$

\begin{abstract}
Third-line sunitinib is occasionally used for selected patients with metastatic renal cell carcinoma (mRCC). The aim of the present study was to evaluate the clinical significance of third-line sunitinib after failure of first-line cytokine therapy and second-line sorafenib in patients with clear-cell mRCC. A total of 14 consecutive patients with clear-cell mRCC treated with third-line sunitinib between December 2008 and February 2012 were enrolled in the present study. Disease control rate (DCR), progression-free survival (PFS), overall survival (OS), and relative dose intensity (RDI) were compared with those of first-line $(n=20)$ and second-line $(n=14)$ sunitinib treatment. The DCR was $42.9 \%$, the median PFS was 12.0 months, and the median OS was 20.0 months for third-line sunitinib; there were no statistically significant differences compared with first-line and second-line sunitinib. The mean RDI was significantly lower for third-line sunitinib compared with first- and second-line sunitinib ( $\mathrm{P}=0.0003$ and 0.0109 , respectively). Therefore, third-line sunitinib is an effective treatment option for selected patients with mRCC, as optimized therapeutic efficacy was obtained with a relatively low dose of sunitinib.
\end{abstract}

\section{Introduction}

Systemic therapy for metastatic renal cell carcinoma (mRCC) has created a notable paradigm shift since the introduction of novel molecular-targeted therapies (1). A standard agent for the treatment of mRCC is sunitinib malate (Sutent; Pfizer Inc.), which is an orally administered, small-molecule, multi-targeted inhibitor of tyrosine kinases, including vascular endothelial growth factor (VEGF) receptor, platelet-derived growth factor receptor, phosphorylation of stem cell factor receptor, Fms-like tyrosine kinase-3, colony-stimulating factor-1 receptor, and RET receptor tyrosine kinases. In a randomized,

Correspondence to: Dr Tetsuo Fujita, Department of Urology, Kitasato University School of Medicine, 1-15-1 Kitasato, Minami-ku, Sagamihara, Kanagawa 252-0374, Japan

E-mail: tfujita@cd5.so-net.ne.jp

Key words: renal cell carcinoma, sequential, sunitinib, third-line multicenter, phase III trial that enrolled 750 patients with previously untreated clear-cell mRCC to receive either sunitinib or interferon (IFN)- $\alpha$, sunitinib was demonstrated to be superior to IFN- $\alpha$ regarding objective response rate (47 vs. $12 \%$, respectively), median progression-free survival (PFS; 11.0 vs. 5.0 months, respectively), and median overall survival (OS; 26.4 vs. 21.8 months, respectively) $(2,3)$. Based on these significant results, sunitinib was approved worldwide for the first-line treatment of clear-cell mRCC.

The oncological outcomes of cytokine therapy for Japanese patients with mRCC have been reported to be more favorable compared with those of Western patients (4). Accordingly, selected patients with mRCC still occasionally receive first-line cytokine therapy in Japan. Furthermore, sorafenib tosylate (Nexavar; Bayer Pharmaceuticals Corporation), which is another standard agent for $\mathrm{mRCC}$, is administered as second-line treatment after failure of cytokine therapy due to its significant results demonstrated in a phase III trial (5). Therefore, the use of third-line sunitinib for selected patients with mRCC should be evaluated, as should the therapeutic efficacy of third-line sunitinib following failure of sequential therapy with cytokines and sorafenib. The aim of the present study was to retrospectively investigate the oncological and therapeutic outcomes of third-line sunitinib for patients with clear-cell mRCC.

\section{Patients and methods}

Patients and treatments. The present study was conducted with the approval of the Kitasato University Medical Ethics Organization (approval no.: KMEO B16-156), which waived the requirement for informed consent due to the retrospective nature of the analyses. Between December 2008 and February 2012, 14 consecutive patients with mRCC treated with third-line sunitinib after sequential use of cytokine therapy and sorafenib were enrolled in the present study. All patients had histologically confirmed clear-cell mRCC. The group comprised 9 men and 5 women with a median age of 62.5 years (range, 52-76 years) at the time of sunitinib initiation. In general, $50 \mathrm{mg}$ sunitinib was administered orally once daily during a 6-week cycle consisting of 4 weeks of treatment followed by a 2-week break. Dose reductions were permitted on the basis of individual tolerability. Comparisons between third-line sunitinib and first- or second-line sunitinib were performed and the results were assessed during the same study 
period. The first-line sunitinib group comprised 20 consecutive patients and the second-line sunitinib group comprised 14 consecutive patients with advanced renal cell carcinoma (a total of 48 consecutive patients). Tumor grading was performed according to the Japanese classification (6).

Response and progression analysis. Response to treatment and disease progression were assessed by the treating physician on the basis of the Response Evaluation Criteria in Solid Tumors (RECIST), version 1.1 (7), with computed tomography or magnetic resonance imaging performed every 4-8 weeks. Adverse events were evaluated by physical examination and laboratory assessments, such as hematological and serum chemistry every 2-4 weeks during treatment with sunitinib, and were graded according to the National Cancer Institute Common Terminology Criteria for Adverse Events, version 4.0 (8).

Disease control rate (DCR) evaluation. Patient charts were retrospectively reviewed. DCR, which was defined as complete response, partial response (PR) and stable disease (SD), was evaluated. PFS, OS and relative dose intensity (RDI) were analyzed. The RDI was calculated as follows: $\mathrm{RDI}=$ cumulative dose $\times 100 / 1,400 \mathrm{mg}$.

Statistical analysis. Analysis of variance and post hoc Fisher's protected least significant difference test were used to evaluate differences of means between cohorts. The Chi-squared test was used to evaluate differences in categorical variables. Non-parametric estimates of survival were performed using Kaplan-Meier curves. Survival curves were generated based on PFS and OS from the initiation of sunitinib administration to the date of disease progression or death. Log-rank tests were used for statistical comparisons. All analyses were performed with StatView version 5.0 (SAS Institute); $\mathrm{P}<0.05$ was considered to indicate statistically significant differences.

\section{Results}

Patient characteristics. The clinical and pathological characteristics of patients administered first-, second- and third-line sunitinib are summarized in Table I. Prior to the initiation of third-line sunitinib, all patients were sequentially treated with first-line cytokine therapy [either IFN- $\alpha$, or IFN- $\alpha$ plus interleukin (IL)-2] and second-line sorafenib. The DCR for first-line cytokine therapy and second-line sorafenib was 71.4 and $50.0 \%$, respectively. The median PFS for first-line cytokine therapy and second-line sorafenib was 10.0 and 5.0 months, respectively.

DCR. Overall, 1 patient (7.1\%) exhibited PR to treatment and 5 patients (35.7\%) had SD according to RECIST. The DCR was $42.9 \%$. First- and second-line sunitinib achieved DCRs of 50.0 and $71.4 \%$, respectively, and the differences were not statistically significant $(\mathrm{P}=0.3429)$.

PFS and OS. Non-parametric estimates of PFS and OS were analyzed by Kaplan-Meier curves for first-, second- and third-line sunitinib. The median PFS for first-, second- and

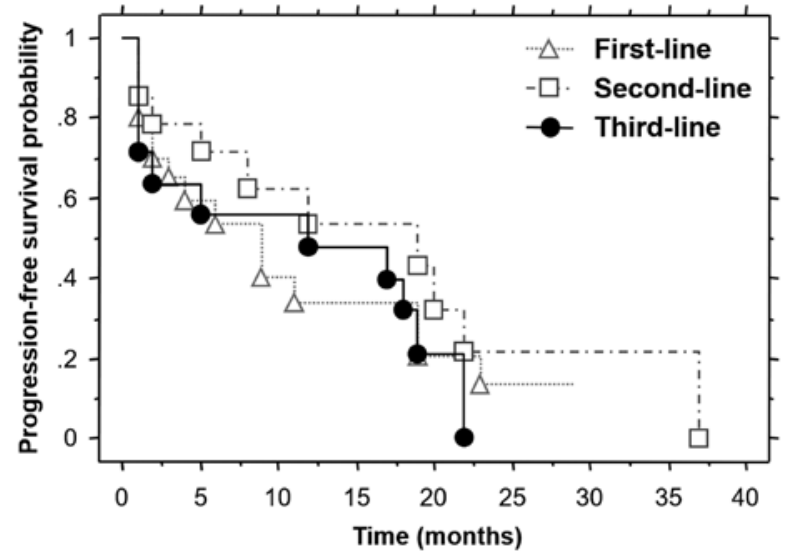

Number at risk

$\begin{array}{lccccccccc}\text { First-line } & 20 & 10 & 6 & 5 & 3 & 2 & 0 & 0 & 0 \\ \text { Second-line } & 14 & 10 & 7 & 5 & 3 & 1 & 1 & 1 & 0 \\ \text { Third-line } & 14 & 7 & 7 & 6 & 1 & 0 & 0 & 0 & 0\end{array}$

Figure 1. Kaplan-Meier progression-free survival curves for patients treated with first-, second- and third-line sunitinib. No statistically significant differences were observed (log-rank $\mathrm{P}=0.5326)$.

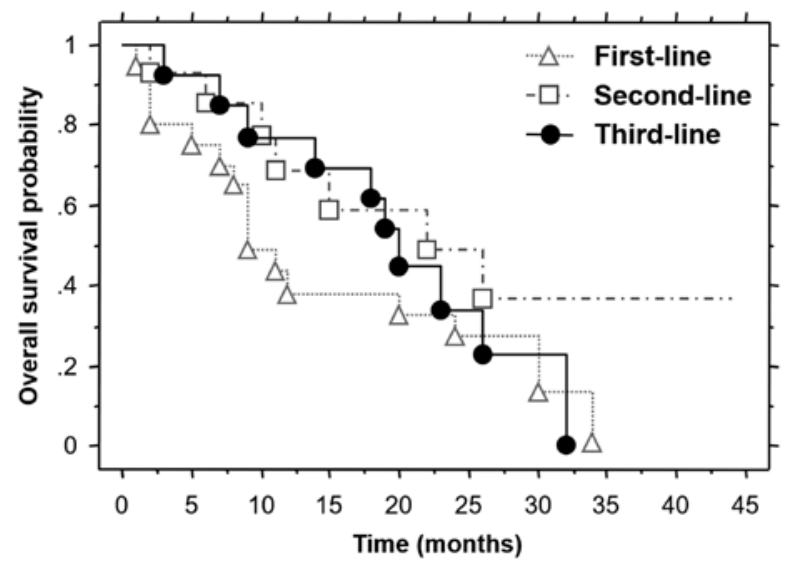

Number at risk

$\begin{array}{lcccccccccc}\text { First-line } & 20 & 15 & 9 & 7 & 6 & 4 & 1 & 0 & 0 & 0 \\ \text { Second-line } & 14 & 13 & 9 & 6 & 6 & 4 & 1 & 1 & 1 & 0 \\ \text { Third-line } & 14 & 12 & 10 & 9 & 5 & 3 & 1 & 0 & 0 & 0\end{array}$

Figure 2. Kaplan-Meier overall survival curves for patients treated with firstsecond- and third-line sunitinib. No statistically significant differences were observed (log-rank $\mathrm{P}=0.2932$ ).

third-line sunitinib was 9.0,19.0 and 12.0 months, respectively (Fig. 1), and the differences were not statistically significant $(\mathrm{P}=0.5326)$. The median OS for first-, second- and third-line sunitinib was 9.0, 22.0 and 20.0 months, respectively (Fig. 2), and the differences were not statistically significant $(\mathrm{P}=0.2932)$.

Adverse events. Adverse events associated with third-line sunitinib treatment are summarized in Table II. The rates of treatment-related edema for first-, second- and third-line sunitinib were 50.0, 21.4 and $7.1 \%$, respectively. Third-line sunitinib was associated with a significantly lower rate of treatment-related edema compared with first- or second-line sunitinib $(\mathrm{P}=0.0193)$. The adverse events of first-line sunitinib were similar with those of second-line sunitinib treatment. 
Table I. Patient characteristics of the three cohorts.

\begin{tabular}{|c|c|c|c|c|}
\hline \multirow[b]{2}{*}{ Characteristics } & \multicolumn{3}{|c|}{ Sunitinib treatment } & \multirow[b]{2}{*}{ P-value } \\
\hline & First-line $(n=20)$ & Second-line $(\mathrm{n}=14)$ & Third-line $(\mathrm{n}=14)$ & \\
\hline $\operatorname{Sex}, \mathrm{n}(\%)$ & & & & 0.6707 \\
\hline Male & $15(75.0)$ & $11(78.6)$ & $9(64.3)$ & \\
\hline Female & $5(25.0)$ & $3(21.4)$ & $5(35.7)$ & \\
\hline Age, years & & & & 0.7408 \\
\hline Median & 65.5 & 66.5 & 62 & \\
\hline Range & $36-75$ & $46-80$ & $52-76$ & \\
\hline Mean \pm standard deviation & $63.3 \pm 9.3$ & $65.6 \pm 9.3$ & $63.9 \pm 7.8$ & \\
\hline ECOG PS, n $(\%)$ & & & & 0.6410 \\
\hline 0 & $13(65.0)$ & $11(78.6)$ & $9(64.3)$ & \\
\hline$\geq 1$ & $7(35.0)$ & $3(21.4)$ & $5(35.7)$ & \\
\hline MSKCC risk classification, $\mathrm{n}(\%)$ & & & & 0.4252 \\
\hline Favorable & $3(15.0)$ & $4(28.6)$ & $2(14.3)$ & \\
\hline Intermediate & $9(45.0)$ & $8(57.1)$ & $9(64.3)$ & \\
\hline Poor & $8(40.0)$ & $2(14.3)$ & $3(21.4)$ & \\
\hline Pretreatment CRP, n (\%) & & & & 0.0869 \\
\hline Normal $(\leq 0.30 \mathrm{mg} / \mathrm{dl})$ & $3(15.0)$ & $7(50.0)$ & $4(28.6)$ & \\
\hline Elevated $(>0.30 \mathrm{mg} / \mathrm{dl})$ & $17(85.0)$ & $7(50.0)$ & $10(71.4)$ & \\
\hline Prior nephrectomy, n (\%) & & & & 0.0004 \\
\hline Yes & $11(55.0)$ & $14(100)$ & $14(100)$ & \\
\hline No & $9(45.0)$ & $0(0)$ & $0(0)$ & \\
\hline Histological classification, n (\%) & & & & 0.2320 \\
\hline Clear-cell & $18(90.0)$ & $14(100)$ & $14(100)$ & \\
\hline Papillary & $2(10.0)$ & $0(0)$ & $0(0)$ & \\
\hline T stage, $\mathrm{n}(\%)$ & & & & 0.5037 \\
\hline $\mathrm{T} 1, \mathrm{~T} 2$ & $8(40.0)$ & $8(57.1)$ & $8(57.1)$ & \\
\hline$\geq \mathrm{T} 3$ & $12(60.0)$ & $6(42.9)$ & $6(42.9)$ & \\
\hline Grade, n (\%) & & & & 0.2288 \\
\hline 1,2 & $8(40.0)$ & $11(78.6)$ & $11(78.6)$ & \\
\hline 3 & $7(35.0)$ & $3(21.4)$ & $3(21.4)$ & \\
\hline Prior cytokine therapy, n (\%) & & & & $<0.0001$ \\
\hline Yes & $0(0)$ & $11(78.6)$ & $14(100)$ & \\
\hline No & $0(0)$ & $3(21.4)$ & $0(0)$ & \\
\hline Prior sorafenib, n (\%) & & & & $<0.0001$ \\
\hline Yes & $0(0)$ & $3(21.4)$ & $14(100)$ & \\
\hline No & $0(0)$ & $11(78.6)$ & $0(0)$ & \\
\hline No. of metastatic sites, $\mathrm{n}(\%)$ & & & & 0.5530 \\
\hline 1 & $6(30.0)$ & $7(50.0)$ & $6(42.9)$ & \\
\hline$\geq 2$ & $13(65.0)$ & $7(50.0)$ & $8(57.1)$ & \\
\hline
\end{tabular}

ECOG, Eastern Cooperative Oncology Group; PS, performance status; MSKCC, Memorial Sloan-Kettering Cancer Center; CRP, C-reactive protein.

$R D I$. The RDI (mean \pm standard deviation) was $69.3 \pm 15.0 \%$ for first-line sunitinib, $63.2 \pm 20.2 \%$ for second-line sunitinib, and $46.1 \pm 16.3 \%$ for third-line sunitinib. Analysis of variance indicated that third-line sunitinib had a significantly lower RDI compared with first- and second-line sunitinib ( $\mathrm{P}=0.0003$ and 0.0109, respectively; Fig. 3).

\section{Discussion}

Third-line sunitinib demonstrated clinical benefits for selected patients with clear-cell mRCC, despite the notable results of phase III clinical trials using first-line sunitinib $(2,3)$. Although sunitinib is widely approved for the first-line 
Table II. Treatment-related toxicity.

NCI CTCAE grade

\begin{tabular}{|c|c|c|c|c|c|c|c|c|}
\hline \multirow[b]{2}{*}{ Toxicity } & \multicolumn{2}{|c|}{ Total } & \multicolumn{2}{|c|}{ Grade 1} & \multicolumn{2}{|c|}{ Grade 2} & \multicolumn{2}{|c|}{ Grade 3} \\
\hline & $\mathrm{n}$ & $\%$ & $\mathrm{n}$ & $\%$ & $\mathrm{n}$ & $\%$ & $\mathrm{n}$ & $\%$ \\
\hline \multicolumn{9}{|l|}{ Adverse events } \\
\hline Hypertension & 6 & 42.9 & 2 & 14.3 & 4 & 28.6 & - & - \\
\hline Hand-foot syndrome & 4 & 28.6 & - & - & 1 & 7.1 & 3 & 21.5 \\
\hline Stomatitis & 5 & 35.7 & 3 & 21.5 & 2 & 14.3 & - & - \\
\hline Fatigue & 6 & 42.9 & 2 & 14.3 & 2 & 14.3 & 2 & 14.3 \\
\hline Diarrhea & 6 & 42.9 & 4 & 28.6 & 1 & 7.1 & 1 & 7.1 \\
\hline Altered taste & 6 & 42.9 & 4 & 28.6 & 2 & 14.3 & - & - \\
\hline Edema & 1 & 7.1 & - & - & - & - & 1 & 7.1 \\
\hline Nausea & 3 & 21.5 & - & - & 1 & 7.1 & 2 & 14.3 \\
\hline Fever & 3 & 21.5 & 3 & 21.5 & - & - & - & - \\
\hline Cholecystitis & 1 & 7.1 & - & - & - & - & 1 & 7.1 \\
\hline Nasal bleeding & 1 & 7.1 & - & - & - & - & 1 & 7.1 \\
\hline \multicolumn{9}{|l|}{ Laboratory abnormalities } \\
\hline Leukopenia & 12 & 85.7 & 2 & 14.3 & 4 & 28.6 & 6 & 42.9 \\
\hline Anemia & 12 & 85.7 & 6 & 42.9 & 4 & 28.6 & 2 & 14.3 \\
\hline Thrombocytopenia & 13 & 92.9 & 4 & 28.6 & 5 & 35.7 & 4 & 28.6 \\
\hline Increased creatinine & 8 & 57.1 & 5 & 35.7 & 2 & 14.3 & 1 & 7.1 \\
\hline Increased alkaline phosphatase & 1 & 7.1 & - & - & - & - & 1 & 7.1 \\
\hline Hypothyroidism & 10 & 71.4 & 1 & 7.1 & 9 & 64.3 & - & - \\
\hline Proteinuria & 8 & 57.1 & 4 & 28.6 & 2 & 14.3 & 2 & 14.3 \\
\hline
\end{tabular}

NCI CTCAE, National Cancer Institute Common Terminology Criteria for Adverse Events.

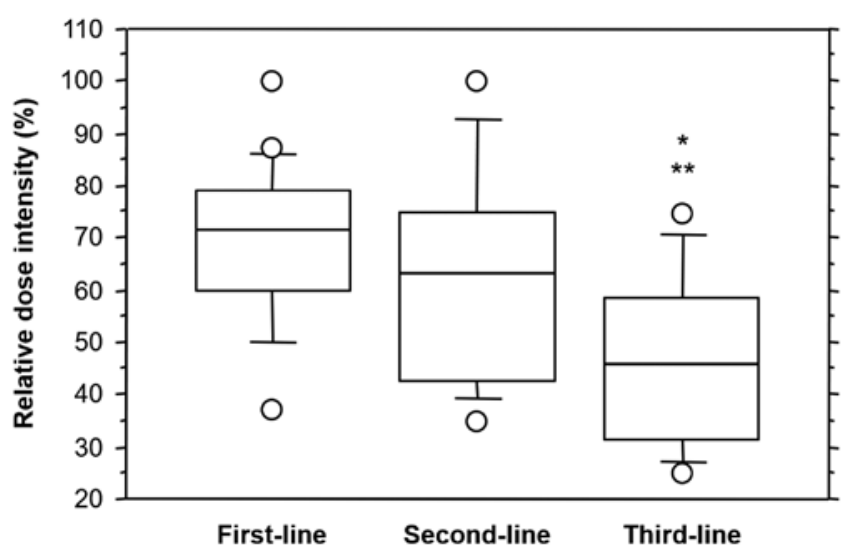

Figure 3. Mean relative dose intensity (RDI) for first-, second- and third-line sunitinib. Third-line sunitinib exhibited a significantly lower RDI compared with first- and second-line sunitinib ( $\mathrm{P}=0.0003$ vs. first-line, ${ }^{* *} \mathrm{P}=0.0109$ vs. second-line). Error bars represent standard deviation.

treatment of clear-cell mRCC, sequential effects after failure of second-line sorafenib have been reported (9-11). In the present study, third-line sunitinib exhibited a DCR of $42.9 \%$, which was not statistically significantly different from that of first-line $(50.0 \%)$ or second-line $(71.4 \%)$ sunitinib $(\mathrm{P}=0.3429)$. The median PFS and OS for third-line sunitinib were 12.0 and 20.0 months, respectively. For first-line sunitinib, the PFS and
OS were 9.0 and 9.0 months, respectively; for second-line sunitinib, the PFS and OS were 19.0 and 22.0 months, respectively. These results were not statistically significantly different ( $\mathrm{P}=0.5326$ and 0.2932 , respectively). To the best of our knowledge, this is the first report of a favorable outcome with the use of third-line sunitinib. Recently, Miyake et al (12) reported the clinical significance of third-line sunitinib for $\mathrm{mRCC}$ after the sequential use of first-line cytokine therapy and second-line sorafenib. The PR rate was $8.6 \%$, and the median PFS and OS were 10.9 and 14.2 months, respectively (12). These results were similar to those of the present study, thus supporting the clinical and oncological efficacy of third-line sunitinib.

Cross-resistance between sorafenib and sunitinib must be addressed. Both agents are small-molecule tyrosine kinase inhibitors that block the intracellular domain of the VEGF receptor. These two agents were developed by similar molecular pathways. However, previous clinical studies demonstrated that there is no definitive cross-resistance between sorafenib and sunitinib (9-11). Eichelberg et al (9) reported that $50.0 \%$ of patients benefited from secondary use of sunitinib. Radiologically confirmed SD or PR was observed in $7(23.3 \%)$ and $8(26.7 \%)$ patients, respectively. The median PFS was 10.3 months (9). Dudek et al (10) reported a DCR of $58.6 \%$ for those who received sunitinib as a second-line agent. The median time to progression was 78 weeks (10). Sablin et al (11) reported that disease control was achieved in 
$66.2 \%$ of patients who were treated with second-line sunitinib following failure of first-line sorafenib. These studies included patients previously treated with various cytokine-based therapies. The clinical benefits of third-line sunitinib in selected patients were revealed. Resistance to single-agent anti-angiogenic therapy may develop through compensatory mechanisms driven by upregulation of plasma VEGF, fibroblast growth factors, ephrin-A1 or angiopoietin-2, or through the development of hypoxia-inducible factor- $\alpha$ independence by activation of angiogenesis with IL-8, cyclooxygenase-2, prostaglandin E2, NF- $\mathrm{B}, \mathrm{RAS}, \mathrm{PI} 3 \mathrm{~K} / \mathrm{Akt}$, or p38 (13).

A prognostic marker for selecting patients who will benefit the most from third-line sunitinib is needed. Dudek et al (10) revealed that Memorial Sloan-Kettering Cancer Center (MSKCC) risk classification (14) and best response to first-line therapy were independently associated with OS in patients receiving sequential therapy with sorafenib and sunitinib. Patients with poor vs. good or intermediate MSKCC risk classification were at higher risk for disease progression $(\mathrm{P}=0.008)$, and patients who had PR or SD during initial treatment were at a slightly lower risk for disease progression during sequential therapy $(\mathrm{P}=0.011)(10)$. Miyake et al $(12)$ reported that performance status (PS), pretreatment $\mathrm{C}$-reactive protein (CRP) level and response to second-line sorafenib were identified as significant predictors of PFS in the univariate analysis; only response to second-line sorafenib was demonstrated to be independently associated with PFS in the multivariate analysis $(\mathrm{P}=0.0032)$. Additionally, the univariate analysis identified significant associations of PS, MSKCC risk classification and pretreatment CRP level with OS. Only PS was an independent predictor of OS in the multivariate analysis $(\mathrm{P}=0.0029)(12)$. We previously demonstrated that normal pretreatment CRP levels predict better PFS with sunitinib treatment, including cohorts receiving third-line treatment (15). However, in the present study, significant results were not obtained by using the Cox proportional hazards regression analysis including variables such as Eastern Cooperative Oncology Group PS, MSKCC risk classification, pretreatment CRP level, response to first-line cytokine therapy, and response to second-line sorafenib (data not shown). Further investigation of prognostic factors to predict response to third-line sunitinib is required.

A significantly lower RDI of third-line sunitinib $(46.1 \pm 16.3 \%)$ was a novel finding of the present study. Patients who received third-line sunitinib experienced optimized therapeutic efficacy from a relatively low dose. An expanded-access trial reported that the mean RDI was $95.2 \%$ (16). However, in Japanese patients, difficulty continuing with the initial dose of sunitinib therapy without drug withdrawal was reported (17). Thus, the initial dose of sunitinib may be reduced in selected patients using third-line sunitinib; dose adjustment for each individual is important.

The median OS of third-line sunitinib was 20.0 months in the present study. The median PFS with cytokine therapy and sorafenib was 10.0 and 5.0 months, respectively. The median survival from the initiation of first-line cytokine therapy was 41.0 months (range, 5-133 months). Patients who received third-line sunitinib experienced long-term survival benefits from these sequential therapies. Several studies have demonstrated that sequential treatment with sorafenib followed by sunitinib achieved longer combined PFS compared with treatment with sunitinib followed by sorafenib $(18,19)$. These results suggest that the sequential use of sorafenib followed by sunitinib after failure of first-line cytokine therapy may be a suitable approach to selected patients with mRCC.

There are currently no standard third-line treatments for mRCC. Some patients received third-line sunitinib after failure of first-line cytokine therapy and second-line sorafenib, as sunitinib was approved after sorafenib. The present study revealed that the outcomes with third-line sunitinib were similar, or even superior, compared to those with first- and second-line sunitinib. The major and most obvious reason is preselection; the patients who are physically fit and have cancer with increased aggressiveness are more likely to benefit from subsequent lines of treatment and have a generally better OS. As the last 12-24 months have brought about marked changes in the first- and second-line treatment of $\mathrm{mRCC}$, the role of salvage sunitinib treatment may become more prominent.

There were certain potential limitations to the present study. First, this was a retrospective single-institutional study and the sample size was small, which may be a major source of bias. Second, it was unclear which patients will benefit the most from third-line sunitinib treatment; in order to confirm its clinical effectiveness and safety, prospective studies on third-line sunitinib with larger sample sizes are needed.

In conclusion, third-line sunitinib was well-tolerated in selected patients with mRCC and it appears to be an effective treatment option for $\mathrm{mRCC}$ following failure of cytokine therapy and sorafenib. Furthermore, optimized therapeutic efficacy was obtained with a relatively low dose of sunitinib. However, careful selection of eligible patients is crucial.

\section{Acknowledgements}

The authors would like to thank Dr Neil M. Singer for providing expert editorial assistance.

\section{Funding}

No funding was received.

\section{Availability of data and materials}

The datasets used and/or analyzed during the present study are available from the corresponding author on reasonable request.

\section{Authors' contributions}

TF designed the present study. TH, MN, KY and MI collected and interpreted the patients' data. TF and KM analyzed the patients' data. TF was a major contributor to writing the manuscript. All authors have read and approved the final version of this manuscript for publication.

\section{Ethics approval and consent to participate}

The present study was approved by the Kitasato University Medical Ethics Organization (approval no. KMEO B16-156). Patient consent was not required for the present study, as it was conducted retrospectively. 


\section{Patient consent for publication}

Not applicable.

\section{Competing interests}

The authors declare that they have no competing interests.

\section{References}

1. Garcia JA and Rini BI: Recent progress in the management of advanced renal cell carcinoma. CA Cancer J Clin 57: 112-125, 2007.

2. Motzer RJ, Hutson TE, Tomczak P, Michaelson MD, Bukowski RM, Rixe O, Oudard S, Negrier S, Szczylik C, Kim ST, et al: Sunitinib versus interferon alfa in metastatic renal-cell carcinoma. N Engl J Med 356: 115-124, 2007.

3. Motzer RJ, Hutson TE, Tomczak P, Michaelson MD, Bukowski RM, Oudard S, Negrier S, Szczylik C, Pili R, Bjarnason GA, et al: Overall survival and updated results for sunitinib compared with interferon alfa in patients with metastatic renal cell carcinoma. J Clin Oncol 27: 3584-3590, 2009.

4. Naito S, Yamamoto N, Takayama T, Muramoto M, Shinohara N, Nishiyama K, Takahashi A, Maruyama R, Saika T, Hoshi S, et al: Prognosis of Japanese metastatic renal cell carcinoma patients in the cytokine era: A cooperative group report of 1463 patients. Eur Urol 57: 317-326, 2010.

5. Escudier B, Eisen T, Stadler WM, Szczylik C, Oudard S, Siebels M, Negrier S, Chevreau C, Solska E, Desai AA, et al: Sorafenib in advanced clear-cell renal-cell carcinoma. N Engl J Med 356: 125-134, 2007.

6. General rule for clinical and pathological studies on renal cell carcinoma, the 4th edition. The Japanese Urological Association, The Japanese Society of Pathology, Japan Radiological Society, 2011.

7. Eisenhauer EA, Therasse P, Bogaerts J, Schwartz LH, Sargent D, Ford R, Dancey J, Arbuck S, Gwyther S, Mooney M, et al: New response evaluation criteria in solid tumours: revised RECIST guideline (version 1.1). Eur J Cancer 45: 228-247, 2009.

8. National Cancer Institute: Cancer Therapy Evaluation Program. https://ctep.cancer.gov/protocolDevelopment/electronic_applications/ctc.htm\#ctc_40. Accessed July 5, 2019.

9. Eichelberg C, Heuer R, Chun FK, Hinrichs K, Zacharias M, Huland $\mathrm{H}$ and Heinzer $\mathrm{H}$ : Sequential use of the tyrosine kinase inhibitors sorafenib and sunitinib in metastatic renal cell carcinoma: A retrospective outcome analysis. Eur Urol 54: 1373-1378, 2008.
10. Dudek AZ, Zolnierek J, Dham A, Lindgren BR and Szczylik C: Sequential therapy with sorafenib and sunitinib in renal cell carcinoma. Cancer 115: 61-67, 2009.

11. Sablin MP, Negrier S, Ravaud A, Oudard S, Balleyguier C, Gautier J, Celier C, Medioni J and Escudier B: Sequential sorafenib and sunitinib for renal cell carcinoma. J Urol 182: 29-34, 2009.

12. Miyake H, Kusuda Y, Harada K, Sakai I and Fujisawa M: Third-line sunitinib following sequential use of cytokine therapy and sorafenib in Japanese patients with metastatic renal cell carcinoma. Int J Clin Oncol 18: 81-86, 2013.

13. Mizukami Y, Kohgo Y and Chung DC: Hypoxia inducible factor-1 independent pathways in tumor angiogenesis. Clin Cancer Res 13: 5670-5674, 2007.

14. Motzer RJ, Bacik J, Murphy BA, Russo P and Mazumdar M: Interferon-alfa as a comparative treatment for clinical trials of new therapies against advanced renal cell carcinoma. J Clin Oncol 20: 289-296, 2002.

15. Fujita T, Iwamura M, Ishii D, Tabata K, Matsumoto K, Yoshida K and Baba S: C-reactive protein as a prognostic marker for advanced renal cell carcinoma treated with sunitinib. Int $\mathbf{J}$ Urol 19: 908-913, 2012

16. Gore ME, Szczylik C, Porta C, Bracarda S, Bjamason GA, Oudard S, Hariharan S, Lee SH, Haanen J, Castellano D, et al: Safety and efficacy of sunitinib for metastatic renal-cell carcinoma: An expanded-access trial. Lancet Oncol 10: 757-763, 2009.

17. Kawashima A, Tsujimura A, Takayama H, Arai Y, Nin M, Tanigawa G, Yasunaga Y, Mukai M, Uemura M, Nakai Y, et al: Importance of continuing therapy and maintaining one-month relative dose intensity in sunitinib therapy for metastatic renal cell carcinoma. Med Oncol 29: 3298-3305, 2012.

18. Porta C, Procopio G, Cartenì G, Sabbatini R, Bearz A, Chiappino I, Ruggeri EM, Re GL, Ricotta R, Zustovich F, et al: Sequential use of sorafenib and sunitinib in advanced renal-cell carcinoma (RCC): An Italian multicentre retrospective analysis of 189 patient cases. BJU Int 108: E250-E257, 2011.

19. Stenner F, Chastonay R, Liewen H, Haile SR, Cathomas R, Rothermundt C, Siciliano RD, Stoll S, Knuth A, Buchler T, et al: A pooled analysis of sequential therapies with sorafenib and sunitinib in metastatic renal cell carcinoma. Oncology 82: $333-340,2012$. 